\title{
An Econometric Model for the Analysis of the Influence of the Refurbishment Costs on Housing Prices
}

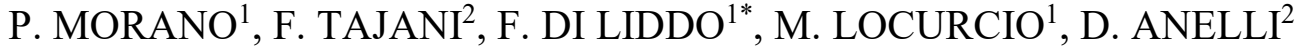 \\ ${ }^{1}$ Department of Civil, Environmental, Land, Building Engineering and Chemistry, \\ Polytechnic University of Bari, Via Edoardo Orabona, 4, 70126, Bari, ITALY \\ ${ }^{2}$ Department of Architecture and Design, Sapienza University of Rome \\ Via Flaminia, 359, 00196, Rome, ITALY
}

\begin{abstract}
With reference to the Italian context, the present research intends to analyze the functional relationships between the unit cost of restructuring and the selling prices in the residential segment. The analysis has been contextualized to the three clusters (Northern Italy, Central Italy, Southern Italy and Islands) in which the Italian territory is commonly divided. The case study concerns 965 residential units sold in the first half of 2019 and located in the 103 provincial capitals. The implemented econometric technique is a datadriven method that employs a genetic algorithm and allows the identification of the most influencing factors among the explanatory variables considered. For each cluster, a model has been selected in order to study the influence of unit cost of restructuring on housing prices.
\end{abstract}

Key-Words: - refurbishment, restructuring, costs, econometric analysis, housing prices, market value

Received: August 7, 2021. Revised: December 30, 2021. Accepted: January 17, 2022. Published: January 18, 2022.

\section{Introduction}

In the international and European context, in the last years a relevant variation in the policies aimed at the renovation of the existing property assets and at its functional reuse through different interventions according to the buildings maintenance conditions has occurred $[1,2,3]$. In this sense, on the basis of the deterioration level, refurbishment projects with partial or total demolition, restoration and/or conservative rehabilitation initiatives, ordinary or extraordinary maintenance operations are planned and implemented. In the cases of large complexes, the redevelopment acquires an urban connotation, by determining a transformation of an entire city portion.

With reference to the Italian territory, the building and infrastructural stock is characterized by a growing obsolescence condition: nearly $60 \%$ of 12.2 million of residential properties included in the 15 th ISTAT population and housing census [4] were built before 1980 and $42.5 \%$ are over 50 years old. Furthermore, currently, a quarter of the entire residential stock consists of properties built before 1946 and $15.0 \%$ was realized before 1919, and 4.1\% of them are in very poor conservation conditions.

In the framework outlined, according to the Goal number 11 defined by 2030 Agenda for Sustainable Development [5] in recent years one of the main challenges in the building sector has been represented by the innovation of construction processes and systems for the refurbishment of the existing real estate assets and the reconversion of properties characterized by energy efficiency, seismic safety, and living comfort inadequate levels according to the current community needs $[6,7]$. In the current financial situation, the building stock renovation constitutes an effective driving force for the national economic recovery: the contraction in the real estate market, in fact, has generated a significant number of unsold properties, unable to be absorbed by reference market without adequate and specific enhancement policies.

The two main questions directly associated to the building assets oldness concern $i$ ) the energy efficiency and ii) the static safety linked to the regional territory seismicity level. It should be highlighted that the relationship between the scarce energy efficiency and the housing stock age could be justified by taking into account that the first law on energy saving related to construction sector dates back to 1977 [8] and, consequently, the houses built before this date (nearly $58.4 \%$ of the total residential property assets [4]) have been realized by neglecting the energy efficiency and static security aspects.

Within the current Italian legislative framework, different fiscal incentives have been drawn up in order to promote the residential stock renovation 
and to financially support the houses owners to start construction work aimed at improving the energy performance indices and at the static safety of the properties. The tax benefit on building refurbishment interventions is regulated by art. 16bis of Presidential Decree No. 917/1986 [9] and subsequent updates and modifications (Law No. 449/1997 [8], Law Decree No. 83/2012 [10], Law Decree No. 63/2013 [11], Law Decree No. 34/2020 [12]). The main fiscal measure provides for a deduction from the income tax - divided into ten annual instalments of the same monetary amount at $50 \%$ for building renovation with a spending limit of $96,000 €$ per residential unit and at $65 \%$ for energy retrofit initiatives aimed at saving primary energy need for a maximum deduction equal to $100.000 €$ or to $60.000 €$ for installation of photovoltaic panels or to $30.000 €$ for the replacement of air conditioning systems (Arts. $14 \mathrm{e}$ 16-ter, Law Decree No. 63/2013 [11] updated in Law No. 90/2013 [13] and art. 1, par. 58 Law No. 178/2020 [14]).

Furthermore, the art. 121 of 2020 Budget Law No. 34 [12] has included $i$ ) the "discount on the invoice" among the benefits provided, i.e. a contribution up to a maximum total intervention amount estimated, advanced by the construction companies and recovered by them in the tax credit form, equal to the deduction due, with the possibility to subsequently assign the credit to other subjects, including credit institutions and other financial intermediaries and $i i$ ) the transfer of a tax credit equal to the intervention amount, with the option of subsequent credit assignment to banks or financial institutions.

Finally, with regards to the energy efficiency interventions (named "Eco-Bonus") and to seismic risk reduction (named "Sisma-Bonus"), the SuperBonus 110\% (art. 119 of Law Decree No. 34/2020 [12], updated by the Law No. 77/2020 [15]) plays a relevant role in the existing properties assets refurbishment, by raising the deduction rate for costs incurred from 1 July 2020 to 30 June 2022 to $110 \%$, for specific energy efficiency and antiseismic interventions, installation of photovoltaic systems or infrastructures for charging electric vehicles. The incentive allows, on the one hand, to trigger new construction sites and, on the other hand, to strongly reduce the energy expenditure for the housing owners, to make their residential properties healthier, static safer and more comfortable and to obtain significant monetary savings.
This research concerns of the topic illustrated. With reference to the existing property assets, the issue of the costs constitutes a relevant question, in particular related to the modalities for the building transformation interventions costs estimation. In this sense, several studies have been developed with the goal to assess the amounts necessary for the project implementation in monetary terms, both by considering realization ex-novo interventions $[16$, $17,18]$ that of reconstruction or redevelopment ones. Furthermore, others studies have been focused on the analysis of the existence of likely changes in the residential selling prices determined by the construction costs for the building realization. These researches, in fact, have aimed at investigating the functional correlations between the construction costs and the housing prices of the properties. A detailed analysis of the existing reference literature has been included in Morano et al. [19] intended to explore the relationships between the construction and refurbishment costs and the properties prices and in which the convenience of refurbishment investments related to housings in the Italian context has been examined.

\section{Aim}

With reference to a study sample of 965 recently refurbished residential properties and collected in 103 Italian provincial capitals, the paper aims at investigating the functional correlation between the refurbishment costs in the residential property segment and the relative selling prices.

Firstly, it should be outlined that in the present research for each city the "ordinary" refurbishment costs have been examined, by taking into account a standard renovation project that concerns the complete reconstructing of the floors, plasters, fixtures and windows and systems (water, heating and electric ones) [19].

In the analysis, the implementation of an econometric technique on the study sample, divided into three territorial clusters - Northern Italy, Central Italy, Southern Italy and Islands [4] - aims to study the different functional relationships between the refurbishment costs and the housing prices. According to the differences in the costs and the income that characterize the three Italian clusters, the analysis intends to compare the outputs obtained for each area in terms of average influence of refurbishment costs in the formation mechanisms of the residential selling prices.

The results obtained could constitute a useful reference for $i$ ) the Public Administrations in order 
to develop fiscal incentives aimed at existing residential properties asset refurbishment and to promote specific strategies in according to the municipality and its socio-economic dynamics and ii) the private market operators to provide a model able to indicate the investment convenience in terms of correlations between the refurbishment costs to bear and the housing prices. In this sense, the model proposed could be represent a tool for monitoring the market mechanisms related to the impacts of renovated properties on housing market processes.

The paper is structured as follows. In the third section, the case study relating to the three property samples located in the three macro-areas mentioned is introduced and the explanatory variables considered are presented. In the fourth section, the econometric methodology adopted for the analysis is explained. In the fifth section, the application of the method to the study sample is carried out and the main functional relationships obtained are interpreted. Finally, the results of the work are discussed in the sixth section.

\section{Case Study}

The analysis is carried out on three study samples consisting of 965 residential properties sold in the first half of 2019 and located in the 103 provincial capitals included in the three clusters (443 properties for the 46 provincial capitals of Northern Italy, 210 properties for the 21 provincial capitals of Central Italy and 312 for the 36 provincial capitals of Southern Italy and the Islands). Within each cluster, the properties considered in the work are residential units located in multi-floor buildings and equally distributed in the three urban areas (central, semicentral and peripheral). Moreover, each housing unit is characterized by an excellent maintenance state and a medium-high energy efficiency rating $(\mathrm{A}+, \mathrm{A}$, B labels).

For each property, the most influencing factors have been analyzed, by considering the indications provided by the housing market operators on the ordinary appreciations detected in the residential sector of the different Italian provincial capitals.

In particular, the variables considered are:

- the property total selling price $(\mathrm{Y})$, expressed in $€$, that represents the dependent variable of the model;

- the total surface of the property (S), expressed in square meters of gross floor area;

- the floor on which the property is located (Lp);
- the presence of the lift [A], considered as a dummy variable $(0=$ absence of the lift; $1=$ presence of the lift);

- the presence of the private parking space $[\mathrm{Pa}]$, assessed as a dummy variable $(0=$ absence of the private parking space; $1=$ presence of the private parking space);

- the "ordinary" unit cost of restructuring [Cr] at the municipal level expressed in $€ / \mathrm{m}^{2}$, defined by taking into account the CRESME database [20]. It should be recalled that in the ordinary restructuring intervention category the operations required to the complete reconstructing of the floors, plasters, fixtures and windows and systems (water, heating and electrical) with medium-high finishing level are included;

- the per capita income [R], calculated on the number of inhabitants in each municipality and expressed in $€$ per year [21];

- the municipal trade area in which the property is located, borrowing the geographical distribution defined by the Italian Revenue Agency [22]: "central" [Zc], "semi-central" [Zs], "peripheral" [Zp]. For each property, the score 1 indicates the belonging to the specific trade area, whereas the score 0 is assigned for all the remaining ones.

\section{Method}

The method implemented in the present research is named Evolutionary Polynomial Regression (EPR). This represents an Automated Valuation Method that derives from the need to exploit the available data through algorithms able to analyze, adapt and effectively replicate the observed phenomena. In this sense, from the detected data, this kind of econometric techniques allows to identify the relationships between the property prices and the most influencing factors in terms of mathematical equations, according to the empirical knowledge of the phenomenon $[23,24,25]$. The methodology applied in the study is a data-driven technique that uses a simple genetic algorithm engine for the combination of symbolic and numerical regression methods by implementing polynomial expressions $[26,27]$.

On the base of experimental data, EPR represents an econometric technique able to generate a set of mathematical models, whose generic structure is given by Eq. (1):

$Y=a_{0}+\sum_{i=1}^{n}\left[a_{i} \cdot\left(X_{1}\right)^{(i, 1)} \cdot \ldots \cdot\left(X_{j}\right)^{(i, j)} \cdot f\left(\left(X_{1}\right)^{(i, j+1)} \cdot \ldots \cdot\left(X_{j}\right)^{(i, 2 j)}\right)\right.$. 
The terms included in the Eq.(1) are described below: $a_{0}$ is the bias, i.e. the constant term, $n$ is the number of additive terms of the polynomial expression (bias excluded), $a_{i}$ are the numerical coefficients to be valued, $X_{j}$ are candidate explanatory variables selected by the algorithm during the elaboration, $(i, l)$ - with $l=(1, \ldots, 2 j)$ - is the exponent of the $l$-th input within the $i$-th term in Eq. (1), $f$ is a function selected in the preliminary phase of EPR elaboration.

In this sense, in fact, the user chooses $i$ ) the structure of the function $f$ among some predefined options, including no function selection and ii) the exponents $(i, l)$ among a set of candidate values (real numbers) by including the value " 0 ". The coefficients of the function are assessed through a Least Squares method. The number and the complexity of the mathematical models that EPR generates during the elaboration phase depend on the possible exponents and the maximum number of additive terms. The EPR technique is able to define several structured mathematical expressions of input-output characterized by different statistical accuracy and, consequently, by various complexity levels in the functional correlations. EPR, in fact, is a procedure consisting of two main steps: the first is aimed at searching the structure of the models by generating a set of algebraic expressions; in the second one, the classical numerical regression method is implemented for the polynomial parameters assessment.

In this sense, the EPR method allows to define a wide set of functional expressions based on their ability to be adapted to the starting data included in the analysis. Furthermore, the automatic process underlying EPR is able to generate different models that simultaneously pursue different objective functions, that are i) to maximize the model accuracy, ii) to maximize the model's parsimony, i.e. to minimize the equation terms number $\left(a_{i}\right)$, iii) to reduce the complexity of the model, i.e. to minimize the explanatory variables number $\left(X_{i}\right)$. Furthermore, in order to verify the statistical accuracy of each equation, the Coefficient of Determination (CoD) [28], the Root Mean Square Error (RMSE), the Mean Absolute Percentage Error (MAPE), the Maximum Absolute Percentage Error (MaxAPE), the Akaike Information Criterion (AIC) are determined.

\section{Application of the Method}

In the present research, EPR has been applied to the case study considering the structure of the generic model identified in Eq. (1) without the function $f$ selected. The maximum number of terms of each expression and the possible positive exponents, selected in the preliminary phase, are equal to ten terms and four exponents $(0,0.5,1,2)$. For each cluster (Northern Italy, Central Italy, Southern Italy and Islands) the model chosen between those provided by the EPR technique are shown below in the Eqs. (2), (3) and (4). The $\mathrm{CoD}$ determined for each mathematical expression is: $69.02 \%$ for the Northern Italy cluster, $73.24 \%$ for the Central Italy one, $61.30 \%$ for the Southern Italy and Islands one.

\section{NORTHERN ITALY}

$\mathrm{Y}=+37833038.9899 \cdot \mathrm{Cr}^{0.5}-22989347.9782 \cdot \mathrm{Cr}$

$-2609967.4989 \cdot \mathrm{R}+2630601.1501 \cdot \mathrm{R}^{2} \cdot \mathrm{Cr}^{2}+$

$-125133.8173 \cdot \mathrm{Zc}^{0.5}+668845.943 \cdot \mathrm{S}^{0.5}++$

$206205.5813 \cdot \mathrm{S} \cdot \mathrm{Lp}^{0.5} \cdot \mathrm{Zs}^{0.5} \cdot \mathrm{R}^{2}-14711383.1007$

\section{CENTRAL ITALY}

$$
\begin{aligned}
& \mathrm{Y}=-2629062.0644 \cdot \mathrm{Cr}^{2}-12038459.6183 \cdot \mathrm{R}+ \\
& 7525570.156 \cdot \mathrm{R}^{2} \cdot \mathrm{Cr}+512112.6293 \cdot \mathrm{Zp} \cdot \mathrm{R}^{2}- \\
& +2433496.387 \cdot \mathrm{S} \cdot \mathrm{R}^{2}-3039297.1181 \cdot \mathrm{S} \cdot \mathrm{Zp}^{0.5} \\
& \mathrm{R}^{0.5} \cdot \mathrm{Cr}-1216503.0159 \cdot \mathrm{S}^{2}+ \\
& +2686261.0046 \cdot \mathrm{S}^{2} \cdot \mathrm{Zp}^{2} \cdot \mathrm{Cr}^{2}+7253037.7497
\end{aligned}
$$

\section{SOUTHERN ITALY}

$$
\begin{aligned}
& \mathrm{Y}=+2984481.9059 \cdot \mathrm{Cr}-1803618.372 \cdot \mathrm{Cr}^{2}+ \\
& 2510863.3907 \cdot \mathrm{S}^{0.5} \cdot \mathrm{R}^{2}+ \\
& +99070.0171 \cdot \mathrm{S} \cdot \mathrm{A}^{0.5} \cdot \mathrm{Zc}^{0.5}-1384468.8745 \cdot \mathrm{S}^{2} \cdot \\
& \mathrm{Lp}^{2} \cdot \mathrm{Pa}^{0.5} \cdot \mathrm{A}^{2} \cdot \mathrm{R}^{2}-1275326.7339
\end{aligned}
$$

It should be noted that the models of Eq. (2), (3) and (4) have been identified among the several models generated by the technique implementation as the best ones for their algebraic form composed by additive terms of simple empirical interpretation, for the good statistical accuracy level and for the inclusion of the explanatory variable "unit cost of restructuring" $(\mathrm{Cr})$ that is the core of the research according to the mentioned aim.

The verification of the empirical consistency of the explanatory variable coefficients' signs has been carried out taking into account the variation of the ith variable analyzed in the variation interval of the 
observed cluster and keeping constant and equal to the respective average value the terms of the other variables.

For all the factors considered in the analysis, the functional correlations between the variables and the total selling price are empirically verified, as they are consistent with the expected phenomena related to the dynamics of the selling price formation. In fact, the total surface of the property (S) is directly linked to the dependent variable of the total selling price, the presence of the lift (A) in the building in which the residential unit is located determines an increase in housing prices. Furthermore, a growth in the per capita income (R) is associated to an increase in prices, and the presence of the private parking space $(\mathrm{Pa})$ is positively appreciation by potential buyers in all clusters considered. Finally, higher selling prices have been observed for properties located in central trade area (C) compared to more peripheral ones $(\mathrm{P})$. Anyway, in the present research the attention is focused on the variable related to the unit cost of restructuring, by taking into account the high interest relating to the topic analysed.

With reference to the three clusters considered, Table 1 shows the functional relationships between the dependent variable selling price and the independent variable "unit cost of restructuring" in terms of $i$ ) the trend obtained, ii) the average percentage variations of the selling prices (average $\%$, iii) the minimum and the maximum percentage variations observed ( $\min \%$ and $\max \%$ ), iv) the percentage variation detected in correspondence of the passage from the minimum unit cost of restructuring found in each cluster and the maximum one $(\min / \max \%)$.

Table 1. Functional relationships between the total selling price and the unit cost of restructuring in the three clusters considered and the total selling price percentage variations detected

\begin{tabular}{|c|c|c|c|c|}
\hline CLUSTER & TREND & $\underset{\%}{\text { AVERAGE }}$ & $\begin{array}{c}\text { MIN \% AND } \\
\text { MAX \% }\end{array}$ & $\begin{array}{c}\text { MIN/MAX } \\
\%\end{array}$ \\
\hline $\begin{array}{l}\text { NORTHERN } \\
\text { ITALY }\end{array}$ & 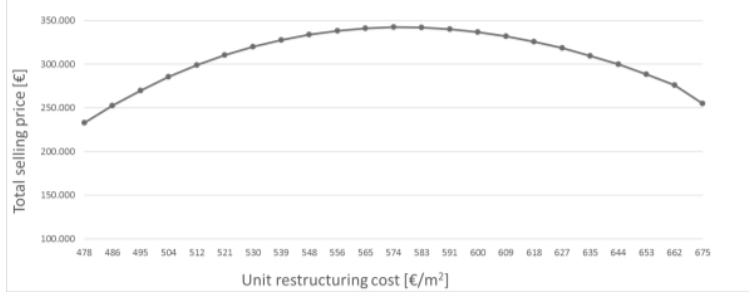 & $+0.372 \%$ & $\begin{array}{l}\mathrm{MIN}=- \\
8.61 \%\end{array}$ & $10.75 \%$ \\
\hline $\begin{array}{l}\text { CENTRAL } \\
\text { ITALY }\end{array}$ & 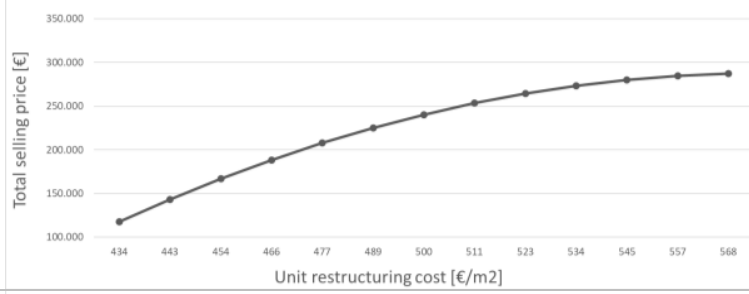 & $+7.03 \%$ & $\begin{array}{l}\text { MAX }= \\
21.85 \%\end{array}$ & $144.13 \%$ \\
\hline $\begin{array}{c}\text { SOUTHERN } \\
\text { ITALY AND } \\
\text { ISLANDS }\end{array}$ & 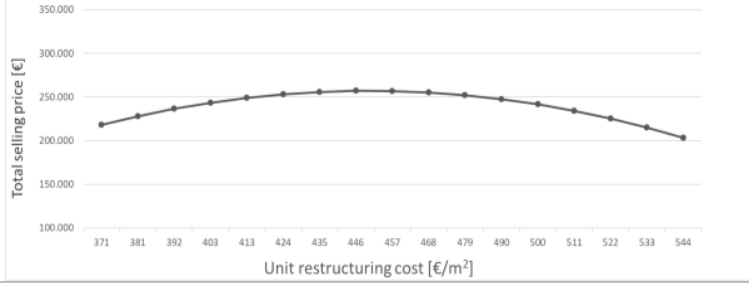 & $-0.48 \%$ & $\begin{array}{l}\mathrm{MIN}=- \\
5.46 \%\end{array}$ & $-6.69 \%$ \\
\hline
\end{tabular}

The graphs in Table 1 express the selling prices trend detected in correspondence of an increase of the unit restructuring cost. For the clusters of Northern Italy and Southern Italy and Islands the growth of the unit restructuring cost determines an increase in the selling prices, until a maximum value beyond which, the increase of the unit restructuring cost leads a decrease in the selling price. In particular, in the Northern Italy macro-area the parabolic trend is more emphasized compared to the curve observed for the Southern Italy and Islands. According to the study sample collected, the graph obtained for the Central Italy cluster shows an initial increase in the total selling price in correspondence of the unit restructuring costs growth and, then, an attenuation of the positive variation corresponding to the highest unit restructuring costs. In this sense, the study highlights that other extrinsic and intrinsic 
factors could cause the trend observed: these variables play a more significant role in the housing price formation mechanisms. For example, the positional factors may strongly influence the residential prices as the characteristics of the urban context in which the property is located, e.g. the accessibility level, the presence of green areas public gardens, parks or urban squares -, the level of security, the presence of local collective services, etc., can determine a reduction in the unit restructuring cost contribution.

\section{Conclusions}

The present research has aimed at analyzing the functional correlations between the total selling prices and the unit cost of restructuring in the three clusters of Northern Italy, Central Italy, Southern Italy and Islands.

With reference to 965 residential properties sold in the first half of 2019 and located in the 103 Italian provincial capitals, the study has focused on the implementation of an econometric technique able to $i$ ) identify the most influencing factors among those considered and ii) explicate the functional links typology and the influence of each variable selected on selling prices in percentage terms. In this sense, in the work three models - one for each cluster have been selected and examined among the several polynomial expressions generated by the methodology in order to determine the contribution of unit cost of restructuring on housing prices.

Therefore, for each study sample a unique model has been identified. This has allowed to verify the existence of a parabolic functional trend of the total housing prices, by taking into account the increase of the unit cost of restructuring for Northern Italy and Southern Italy and Islands, whereas a positive and growing trend for Central Italy. In particular, for the Central Italy cluster a progressive attenuation of the incidence of the restructuring costs variable on the prices has been observed in correspondence of the highest costs detected in the study sample analyzed.

The topic of the present research is part of a current and relevant issue associated to the significant need to refurbishment the existing residential property assets in order to adapt it $i$ ) to the regulatory standards, $i i)$ to the national laws and iii) to the requirements of the community. The methodological approach illustrated could be a valid tool for Public Administrations and private investors for monitoring the restructuring costs component influence in the residential selling price formation mechanisms. It should be outlined, in fact, that the approach adopted in the analysis is flexible and easily applicable to any geographical context and to the same urban territory for the update of results and the determination of relevant variations, also by taking into account the several fiscal incentives developed to promote the renovation of the residential buildings. By keeping the same aim, further insights of the present research may concern the development of other methodologies for the analysis of the functional relationships between the unitary restructuring costs and the final selling prices, in order to compare the outputs and to verify the reliability of results obtained in this study.

\section{References:}

[1] Bhuiyan SI, Jones K and Wanigarathna N 2015 An approach to sustainable refurbishment of existing building 31st annual ARCOM Conf. 1093-1102

[2] Highfield D and Gorse C. 2009 Refurbishment and upgrading of buildings (Routledge)

[3] Hanh HT, Nga LTV, Huy DTN, Lan LM and Dat PM 2020 The Quantified Analysis of Causes of Market Risk Fluctuations in the Group of Construction, Real Estate and Construction Material Companies in Vietnam During and after the Global Crisis 2007-2011 WSEAS Transactions on Environment and Development 16 189-197

[4] www.istat.it

[5] United Nations. Agenda 20302015 Available online: https://unric.org/it/agenda-2030/

[6] Pombo O, Rivela B and Neila J 2016 The challenge of sustainable building renovation: assessment of current criteria and future outlook J. of Clean. prod. 123 88-100

[7] www.enea.it

[8] Law No. 449/1997 - Misure per la stabilizzazione della finanza pubblica

[9] Presidential Decree No. 917/1986

[10] Law Decree No. 83/2012 - Misure urgenti per la crescita del Paese

[11] Law Decree No. 63/2013 - Disposizioni urgenti per il recepimento della Direttiva 2010/31/UE del Parlamento europeo e del Consiglio del 19 maggio 2010, sulla prestazione energetica nell'edilizia per la definizione delle procedure d'infrazione avviate dalla Commissione europea, nonche' altre disposizioni in materia di coesione sociale.

[12] Law Decree No. 34/2020 - Decreto Rilancio

[13] Law No. 90/2013

[14] Law No. 178/2020 
[15] Law No. 77/2020

[16] Zhang S, Migliaccio GC, Zandbergen PA and Guindani M 2014 Empirical assessment of geographically based surface interpolation methods for adjusting construction cost estimates by project location Journal of Construction Engineering and Management 140(6) 04014015

[17] Velumani $P$ and Nampoothiri NVN 2019 Analysis of construction cost prediction studies-global perspective International Review of Applied Sciences and Engineering 10(3) 275-281

[18] Zhao L, Zhang W and Wang W 2019 Construction Cost Prediction Based on Genetic Algorithm and BIM International Journal of Pattern Recognition and Artificial Intelligence 34(07) 2059026.

[19] Morano P, Tajani F, Di Liddo F and Anelli D 2020 A feasibility analysis of the refurbishment investments in the Italian residential market Sustainability 12(6) 2503

[20] www.cresme.it

[21] www.finanze.gov.it

[22] www.agenziaentrate.gov.it

[23] Metzner S and Kindt A 2018 Determination of the parameters of automated valuation models for the hedonic property valuation of residential properties: a literature-based approach. International Journal of Housing Markets and Analysis

[24] Faishal Ibrahim M, Jam Cheng F and How Eng K 2005 Automated valuation model: an application to the public housing resale market in Singapore Property Management 23(5) 357373

[25] Kociu L and Kodra K 2021 Using the Econometric Models for Identification of Risk Factors for Albanian SMEs (Case study: SMEs of Gjirokastra region) WSEAS Transactions on Business and Economics 18 163-170

[26] Giustolisi O and Savic D 2009 Advances in data-driven analyses and modelling using EPRMOGA J. of Hydr. 11(3-4)) 225-236.

[27] Morano P, Guarini MR, Tajani F, Di Liddo F and Anelli D 2019 Incidence of Different Types of Urban Green Spaces on Property Prices. A Case Study in the Flaminio District of Rome (Italy) International Conference on Computational Science and Its Applications (Cham Springer vol 11622) pp 23-34

[28] Morano P, Guarnaccia C, Tajani F, Di Liddo F and Anelli D 2020 An analysis of the noise pollution influence on the housing prices in the central area of the city of Bari Journal of Physics: Conference Series (IOP Publishing vol 1603(1)) p 012027.

\section{Creative Commons Attribution License 4.0 (Attribution 4.0 International, CC BY 4.0)}

This article is published under the terms of the Creative Commons Attribution License 4.0 https://creativecommons.org/licenses/by/4.0/deed.en US 